\title{
Dose- and Time-Dependent Cytotoxicity of Layered Black Phosphorus in Fibroblastic Cells
}

\author{
Su-Jin Song ${ }^{1,+}$, Yong Cheol Shin ${ }^{2,+}$ (D) , Hyun Uk Lee ${ }^{3}$, Bongju Kim ${ }^{4}$ (D), Dong-Wook Han ${ }^{1, * \text { (D) }}$ \\ and Dohyung Lim ${ }^{5, *}$ \\ 1 Department of Cogno-Mechatronics Engineering, College of Nanoscience \& Nanotechnology, \\ Pusan National University, Busan 46241, Korea; songsj86@gmail.com \\ 2 Research Center for Energy Convergence Technology, Pusan National University, Busan 46241, Korea; \\ choel15@naver.com \\ 3 Advanced Nano-surface Research Group, Korea Basic Science Institute (KBSI), Daejeon 34133, Korea; \\ leeho@kbsi.re.kr \\ 4 Dental Life Science Research Institute, Seoul National University Dental Hospital, Seoul 03080, Korea; \\ bjkim016@gmail.com \\ 5 Department of Mechanical Engineering, Sejong University, Seoul 05006, Korea \\ * Correspondence: nanohan@pusan.ac.kr (D.-W.H.); dli349@sejong.ac.kr (D.L.); \\ Tel.: +82-51-510-7725 (D.-W.H.); +82-2-3408-3672 (D.L.) \\ + Those authors contributed equally to this work.
}

Received: 10 May 2018; Accepted: 4 June 2018; Published: 6 June 2018

\begin{abstract}
Black phosphorus (BP) is a monolayer/multilayer two-dimensional (2D) nanomaterial, which has recently emerged as one of the most attractive 2D nanomaterials due to its fascinating physicochemical and optoelectronical properties. Layered BP may have promising applications in biomedical fields, such as drug delivery, photodynamic/photothermal therapy and bioimaging, although its intrinsic toxicity has not been fully elucidated yet. In the present study, the cytotoxicological effects of layered BP on both cell metabolic activity and membrane integrity were investigated. Layered BPs were prepared using a modified ultrasonication-assisted solution method, and their physicochemical properties were characterized. The dose- and time-dependent cytotoxicity of layered BP was assessed against L-929 fibroblasts. Our findings indicate that the cytotoxicity of BPs is proportionally dependent on their concentration and exposure time, which is affected by the oxidative stress-mediated enzyme activity reduction and membrane disruption. On the other hand, layered BPs did not exhibit significant cytotoxicity at concentrations lower than $4 \mu \mathrm{g} / \mathrm{mL}$. Therefore, it is suggested that layered BPs can be effectively utilized as therapeutic delivery carriers and imaging agents.
\end{abstract}

Keywords: black phosphorus; 2D nanomaterial; cytotoxicity; biomedical application

\section{Introduction}

Over the last decade, tremendous research has been conducted to understand and explore the various types of two-dimensional (2D) nanomaterials. This research has found that $2 \mathrm{D}$ nanomaterials have a promising potential in a variety of applications, such as optoelectronics, photonics, energy storage and conversion, and biomedicine [1,2]. Among monolayer/multilayer 2D nanomaterials, layered black phosphorus (BP) has recently emerged as an attractive novel one due to its distinct structure, with phosphorenes stacked in several layers via van der Waals forces, and has been acknowledged as one of the most stable allotropes of the phosphorus family [3-8]. Some studies have already shown the potential of BP in biomedical applications, such as drug delivery, photodynamic/photothermal therapy and bioimaging [1,9-13]. However, several controversial results regarding the toxicity of BP 
have been reported, which means that an in-depth understanding of the cytotoxicity and underlying mechanism of $\mathrm{BP}$ is of utmost importance.

A series of studies reported that layered BP has little to no toxic effects, which means that it can be employed as a biomedical material $[1,6,13]$. It has been found that, while the BPs can induce cell apoptosis and necrosis owing to the transient intracellular reactive oxygen species (ROS)-mediated oxidative stress, the induced oxidative stress can be gradually restored to normal levels with no long-term inflammatory reaction or obvious damage to an in vivo mouse model [14]. Moreover, $\mathrm{BP}$ nanosheets can be used as drug delivery vehicles because they have $\mathrm{pH}$ - or photo-responsive drug release characteristics as well as a high drug loading efficiency [1,9]. Additionally, BP has been found to possess both outstanding near-infrared photothermal performance and photodynamic activity, which allows it to be utilized for photothermal and photodynamic therapy [9-12,15]. However, although these studies on the biomedical potential of $\mathrm{BP}$ could provide valuable guidelines for the essential understanding of the biological effects of BP, the issue of the potential toxicity of BP remains unresolved. In particular, the toxicity of layered BPs is highly varied depending on their concentration, size, shape, surface chemistry, and exposure time, which is similar to the other 2D nanomaterials, such as graphene and its derivatives $[14,16,17]$. Therefore, prior to the use of layered BP in biomedical applications, it is urgently necessary to investigate its toxicological effects. Hence, in the present study, we assessed the cytotoxicity of layered BP on fibroblastic cells according to its concentration and exposure time, using cytotoxicity assays with different end-points, including the cell metabolic activity, membrane integrity and intracellular ROS production. Our findings revealed that layered BPs showed dose- and time-dependent cytotoxicity, which are caused by oxidative stress-mediated enzyme activity reduction and membrane disruption, but they did not exhibit significant cytotoxicity at a low concentration. These dose- and time-dependent cytotoxicity profiles of layered BPs can be quite informative and useful for their development as biocompatible therapeutic delivery carriers and imaging agents.

\section{Materials and Methods}

\subsection{Preparation and Characterization of Layered $B P$}

Layered BP was prepared by exfoliation of bulk BP crystals using a modified ultrasonication-assisted solution method, as described elsewhere [13]. Fourier transform infrared (FT-IR) spectroscopy was used to characterize the layered BP. The FT-IR spectrum of layered BP was collected using an FT-IR spectroscope (Nicolet Co., Madison, WI, USA) with a resolution of $4.0 \mathrm{~cm}^{-1}$ and 16-times scanning in the wavelength range of $750-4000 \mathrm{~cm}^{-1}$. The surface topography of layered BP was analyzed by atomic force microscopy (AFM; NX10, Park Systems Co., Suwon, Korea) in air at room temperature. Imaging was carried out in non-contact mode with a Multi 75 silicon scanning probe at a resonant frequency of $\sim 300 \mathrm{kHz}$. The average hydrodynamic size of layered BPs was determined using a Zetasizer (Nano ZS, Malvern Instruments, Worcestershire, UK).

\subsection{In Vitro Assays for Cytotoxicity Evaluation of Layered BP}

L-929 fibroblastic cells were routinely cultured in Dulbecco's modified Eagle's Medium (DMEM, Welgene, Daegu, Korea) supplemented with 10\% fetal bovine serum (Welgene) and $1 \%$ antibiotic-antimycotic solution (Sigma-Aldrich Co., Saint Louis, MO, USA) at $37^{\circ} \mathrm{C}$ in a humidified atmosphere containing 5\% $\mathrm{CO}_{2}$. The cell viability of L-929 cells, treated with layered BP for $24 \mathrm{~h}$, $48 \mathrm{~h}$ and $72 \mathrm{~h}$, was assessed by a cell counting kit-8 (CCK-8) assay (Dojindo, Kumamoto, Japan) according to the manufacturer's instructions. Briefly, L-929 fibroblasts were seeded at a density of $1 \times 10^{4}$ cells $/ \mathrm{mL}$ on a 96-well plate and incubated for $24 \mathrm{~h}$. Subsequently, the cells were treated with various concentrations of layered BP suspended in culture medium ( 0 to $125 \mu \mathrm{g} / \mathrm{mL})$ and then incubated with a CCK-8 solution for the last $2 \mathrm{~h}$ of the culture period $(24 \mathrm{~h}, 48 \mathrm{~h}$ and $72 \mathrm{~h})$ at $37{ }^{\circ} \mathrm{C}$ in the dark. The absorbance was measured at $450 \mathrm{~nm}$ using an enzyme-linked immunosorbent assay (ELISA) reader (SpectraMax ${ }^{\circledR}$ 340, Molecular Device Co., Sunnyvale, CA, USA). The cell viability was 
determined to be the percentage ratio of the absorbance values in the cells (incubated with layered $\mathrm{BP}$ ) to those in untreated control groups $(0 \mu \mathrm{g} / \mathrm{mL})$.

The cell membrane integrity was investigated by monitoring the release of lactate dehydrogenase (LDH) using an LDH assay kit (Takara Bio Inc., Shiga, Japan). After $24 \mathrm{~h}$ of incubation with various concentrations of layered BP, the supernatant from each cell culture was transferred to a new 96-well plate. Next, the LDH assay solution was added to each well and then incubated for $30 \mathrm{~min}$ at room temperature in the dark. The absorbance was measured at $490 \mathrm{~nm}$ using an ELISA reader.

The intracellular ROS production was detected using an ROS assay kit (OxiSelect ${ }^{\mathrm{TM}}$; Cell Biolabs, Inc., San Diego, CA, USA). Typically, L-929 cells were plated in a 96-well plate $\left(1 \times 10^{4}\right.$ cells $\left./ \mathrm{mL}\right)$ and incubated for $24 \mathrm{~h}$. The cells were treated with increasing concentrations of layered BP for $24 \mathrm{~h}$. Each cell culture was washed with Dulbecco's phosphate-buffered saline (DPBS, Gibco, Rockville, MD, USA) and then incubated with $2^{\prime}, 7^{\prime}$-dichloroflurorescein diacetate (DCFH-DA), a cell-permeable fluorogenic probe, for $30 \mathrm{~min}$ at $37^{\circ} \mathrm{C}$ in the dark. The cells were then imaged using an inverted fluorescence microscope (IX81, Olympus, Melville, NY, USA); the fluorescence intensity was determined by a fluorescence plate reader (VICTOR ${ }^{3}$ Multilabel Counter, PerkinElmer, Inc., Waltham, MA, USA) with excitation and emission wavelengths of $480 \mathrm{~nm}$ and $530 \mathrm{~nm}$, respectively. The fluorescence intensity was expressed as the fold-increase over the values of the untreated control groups.

For morphological observations, the time-lapse images of L-929 cells treated with $10 \mu \mathrm{g} / \mathrm{mL}$ of layered BP were acquired every $1 \mathrm{~h}$ for $12 \mathrm{~h}$ of incubation. The percentage of live cells was estimated by calculating the ratio of the number of attached cells, defined as cells with a spindle-like morphology (i.e., aspect ratio larger than 1) or specialized subcellular structures, such as lamellipodia, filopodia, stress fibers, and membrane protrusions, to the total number of cells [18-22].

\subsection{Statistical Analysis}

All variables were tested in three independent cultures for each experiment, which were repeated twice $(n=6)$. All presented data were expressed as average \pm standard deviation. Statistical comparisons were carried out by a one-way analysis of variance (SAS Institute Inc., Cary, NC, USA), followed by a Bonferroni test for multiple comparisons. A value of $p<0.05$ was considered statistically significant.

\section{Results and Discussion}

\subsection{Characteristics of Layered $B P$}

The physicochemical properties of layered BP were characterized by FT-IR spectroscopy and AFM (Figure 1). The FT-IR spectrum of layered BP showed the characteristic peaks of BP crystals (Figure 1a). A noticeable peak was observed near $1000 \mathrm{~cm}^{-1}$, attributed to the stretching vibrations of $\mathrm{P}-\mathrm{O}$ [23]. The peaks found near 1140 and $1620 \mathrm{~cm}^{-1}$ represented the $\mathrm{P}=\mathrm{O}$ stretching modes of layered $\mathrm{BP}[23,24]$. On the other hand, broad absorption bands were observed, ranging from $2400 \mathrm{~cm}^{-1}$ to $3500 \mathrm{~cm}^{-1}$, which could be attributed to the $\mathrm{CO}_{2}$ stretching and $\mathrm{OH}$ stretching vibrations due to exposure of the layered BP to ambient atmosphere. The surface topographic image of layered BP is presented in Figure $1 \mathrm{~b}$. Most layered BP were found to have a 2D layer structure, and the average height was about $6.87 \pm 0.58 \mathrm{~nm}$ (Figure 1b,c). Considering the thickness of the BP monolayer $(0.53 \mathrm{~nm})$, the layered BP was composed of several BP monolayers [25]. Moreover, the hydrodynamic size of 2D nanomaterials is of great importance in biomedical applications, because it has a marked effect on the interactions between 2D nanomaterials and cells [17,26-29]. The hydrodynamic size of the BPs used in the present study was found to be $960 \pm 303 \mathrm{~nm}$ (Figure 1d). 
(a)

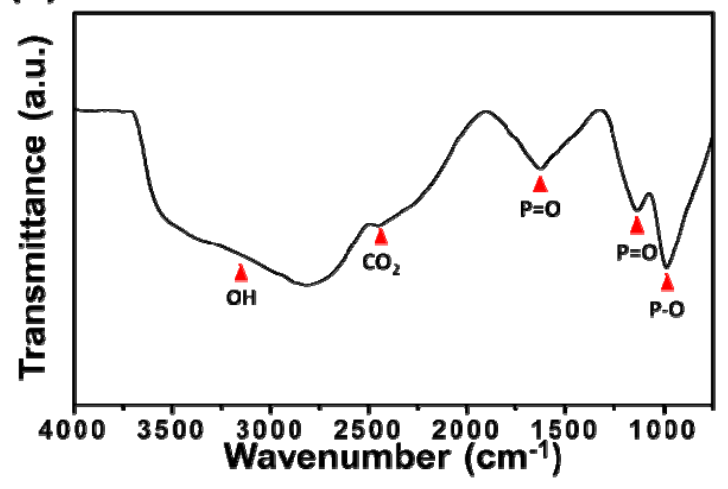

(c)

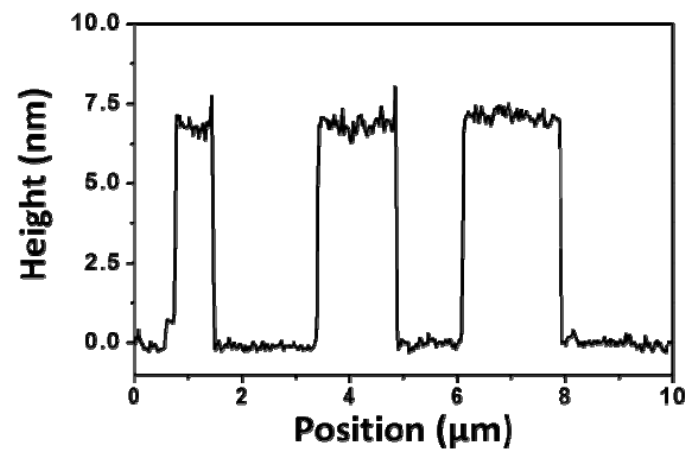

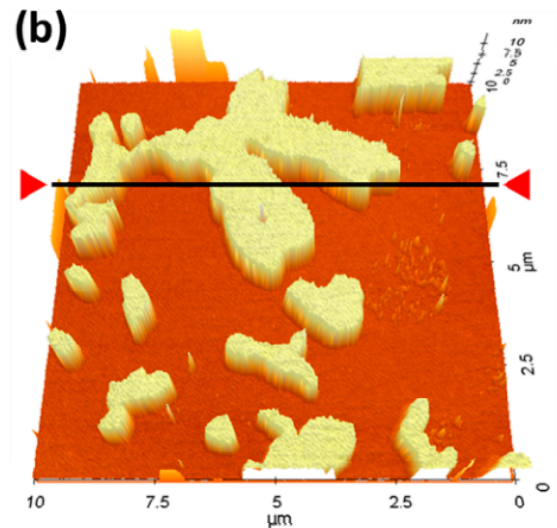

(d)

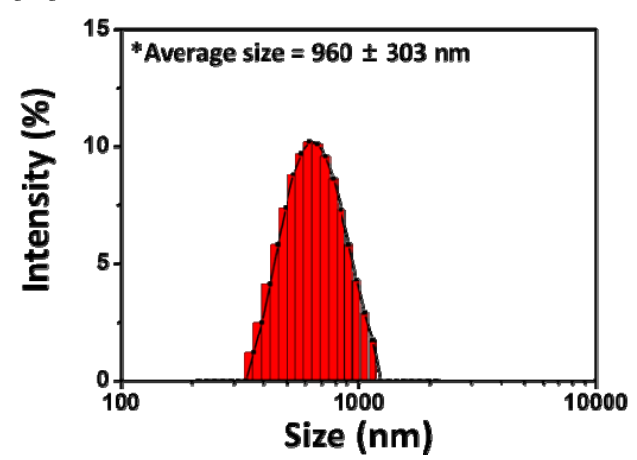

Figure 1. Characterizations of layered BP. (a) FT-IR spectrum of layered BP; (b) AFM image and (c) the height profile of layered BP along the black line marked in (b); (d) Hydrodynamic size distribution histogram of layered BP.

\subsection{Dose-Dependent Cytotoxicity of Layered BP}

To investigate the cytotoxic effects of layered BP on L-929 fibroblasts according to its concentration, cells were treated with increasing concentrations of layered BP (0 to $125 \mu \mathrm{g} / \mathrm{mL}$ ) for $24 \mathrm{~h}$, and the morphology of the cells was observed (Figure 2a). There were no significant differences in the number and morphology of L-929 fibroblasts at concentrations of up to $4 \mu \mathrm{g} / \mathrm{mL}$ of layered BP. On the other hand, the cells with aggregated BPs exhibited an abnormal morphology and a significant decrease in cell number at concentrations higher than $8 \mu \mathrm{g} / \mathrm{mL}$, clearly indicating that layered BPs exhibit dose-dependent cytotoxicity. From the CCK- 8 assay, based on the cell metabolic activity (Figure $2 b$ ), it was found that the cell viability of L-929 fibroblasts decreased as BP concentration increased. At relatively low concentrations $(\sim 4 \mu \mathrm{g} / \mathrm{mL})$, over $82 \%$ of fibroblasts were viable, whereas the cell viability of the control at $62 \mu \mathrm{g} / \mathrm{mL}$ decreased to approximately $37 \%$. These findings are inconsistent with previous reports, which found that BP derivatives, including BP nanosheets and nanodots, were nontoxic to several types of cells even when BP concentration was as high as $1000 \mu \mathrm{g} / \mathrm{mL}[1,6,9,13]$. These conflicting results may be due to size effects. It was demonstrated that layered BPs show a size-dependent cytotoxicity; larger BPs (with lateral size of $\sim 880 \mathrm{~nm}$ ) were more cytotoxic than smaller ones (with lateral size of $\sim 210 \mathrm{~nm}$ ) [17]. As shown in Figure 1d, the average lateral size $(\sim 960 \pm 303 \mathrm{~nm})$ of layered BPs used in this study was relatively larger than that used in other investigations, which can result in greater toxic effects on cells. 
(a)
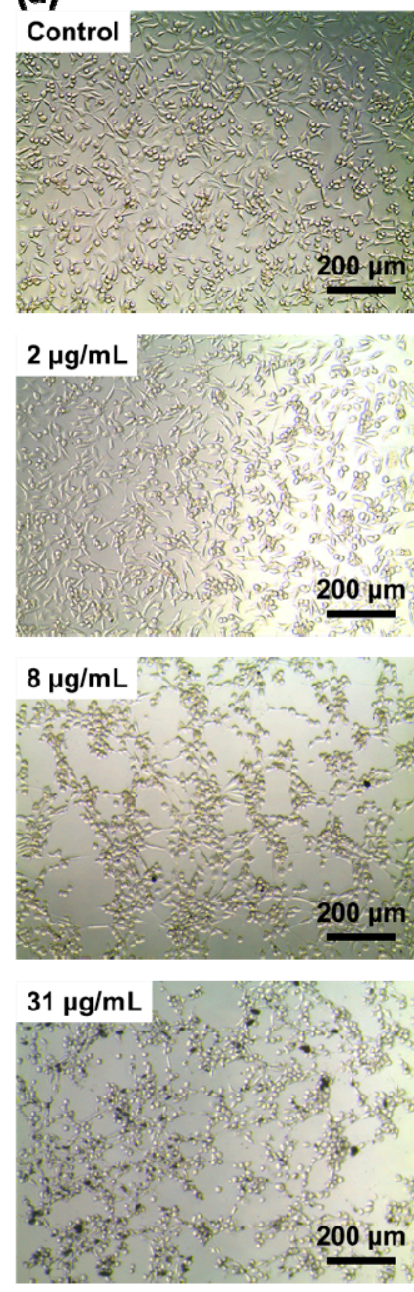
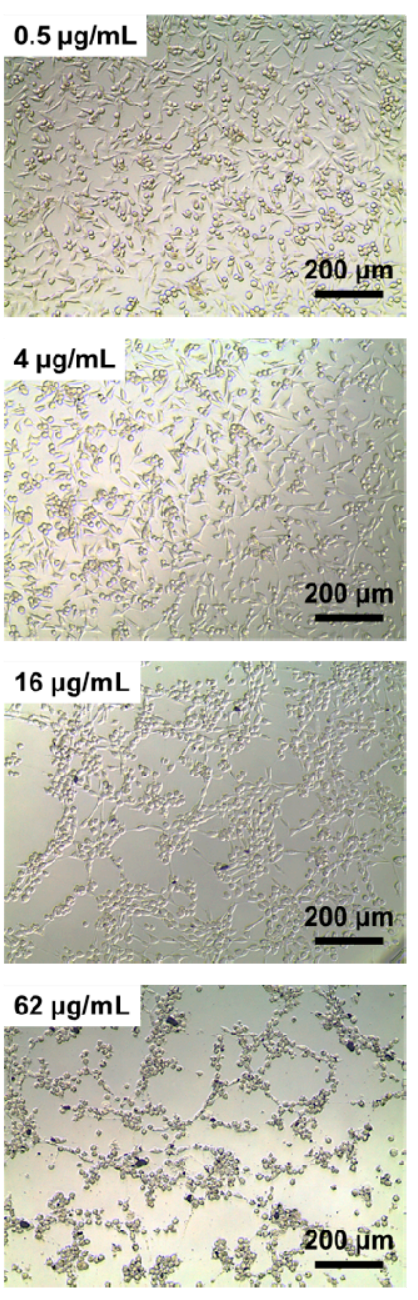

(b)

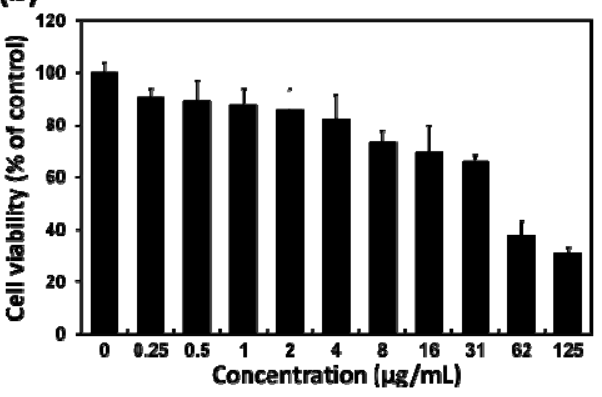

(c)

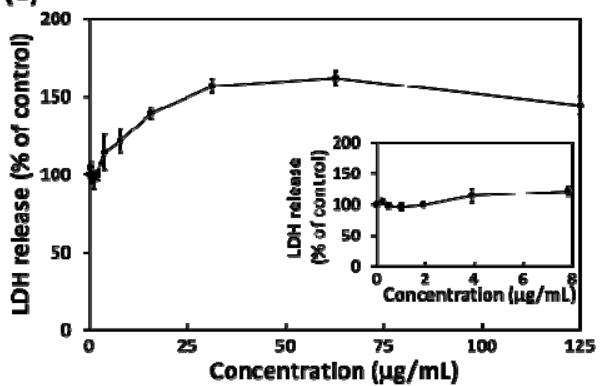

(d)

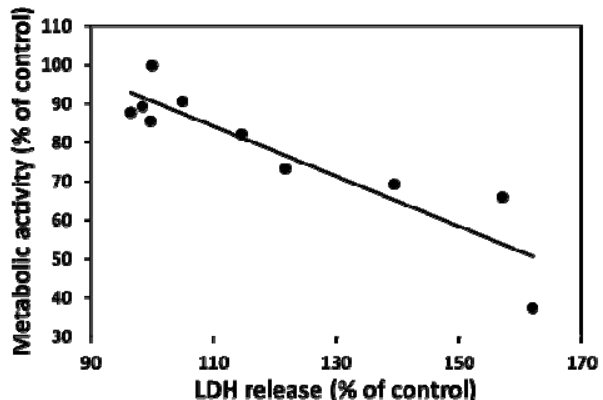

Figure 2. (a) Representative optical microscopy images of L-929 fibroblasts cultured with layered BP $(0,0.5,2,4,8,16,31$ and $62 \mu \mathrm{g} / \mathrm{mL})$; (b) Cell viability and (c) LDH release profile of L-929 fibroblasts after $24 \mathrm{~h}$ of incubation with various concentrations of layered BP; (d) Correlation coefficient plot between metabolic activity and LDH release for cells cultured with layered BP at concentrations ranging from 0 to $62 \mu \mathrm{g} / \mathrm{mL}$.

\subsection{Membrane Disruption and ROS Production Induced by Layered BP}

On the other hand, interesting results were found concerning the cytotoxicity of layered BPs. The cytotoxic effects of layered BPs can be ascribed to membrane disruption [17,30]. Therefore, we investigated the cytotoxicity of layered BPs using LDH assays based on the cell membrane integrity (Figure 2c). The extracellular release of LDH has been extensively used for investigating cell membrane integrity, because LDH, a stable cytoplasmic enzyme, can only be released into extracellular fluids upon plasma membrane disruption [31]. As shown in Figure 2c, a significant LDH release was detected at high concentrations of layered BP $(\geq 16 \mu \mathrm{g} / \mathrm{mL})$. The LDH release increased to approximately $140 \%$ of the control at $16 \mu \mathrm{g} / \mathrm{mL}$ of BP, indicating that high concentrations of layered BPs induced a significant membrane disruption. A slight decrease in $\mathrm{LDH}$ release, observed at $125 \mu \mathrm{g} / \mathrm{mL}$, can be due to the decrease in the total cell number. For CCK-8 and LDH assay results, the calculated value of the corresponding correlation coefficient was -0.91 (Figure 2d), implying that the effects of layered BP on cell metabolic activity and membrane integrity were shown to have a high negative correlation.

At the same time, the dose-dependent cytotoxicity of layered BPs can also be due to oxidative stress. To further investigate the cytotoxicity of layered BPs, the effects of BPs on intracellular ROS 
generation were evaluated using an ROS-sensitive fluorogenic probe DCFH-DA. The DCFH-DA, a cell-permeable fluorophore, can be readily diffused into cells and subsequently deacetylated by cellular esterases to non-fluorescent DCFH ( $2^{\prime}, 7^{\prime}$-dichlorodihydrofluorescin). The internalized DCFH is quickly oxidized to highly fluorescent DCF by intracellular ROS. Hence, the intracellular fluorescence of DCF reflects the oxidative stress attributed to the intracellular ROS production. As shown in Figure 3a, the minimal fluorescence was detected at low concentrations of layered BP $(\leq 4 \mu \mathrm{g} / \mathrm{mL})$, while obvious green fluorescence was detected in L-929 cells after incubation with concentrations of layered BP higher than $8 \mu \mathrm{g} / \mathrm{mL}$. In addition, the fluorescence intensity was significantly $(p<0.05)$ enhanced with increasing concentrations of layered BPs (Figure $3 b$ ). It has been documented that the cytotoxicity of BP nanomaterials causes oxidative stress, such as the reduction of enzyme activity, lipid peroxidation and DNA breaks, caused by intracellular ROS production [14]. Thus, even though the size of the layered BP used in the present study was different from that used in previous studies, the cytotoxicity of layered BPs is proportionally dependent on their concentration, which can be attributed to the reduction of metabolic activity owing to oxidative stress. From our in vitro cytotoxicity assay results with different end-points (the cell metabolic activity, membrane integrity and intracellular ROS production), it was revealed that the dose-dependent cytotoxicity of layered BPs was due to both membrane disruption and oxidative stress-mediated metabolic activity reduction.

(a)
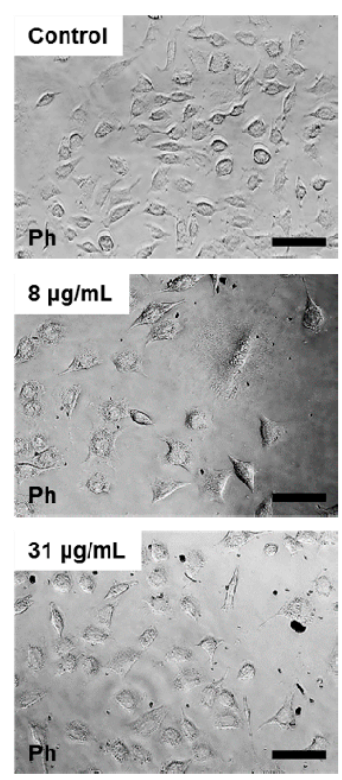
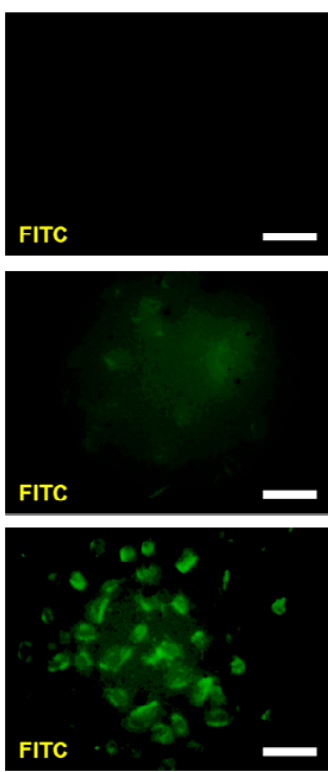
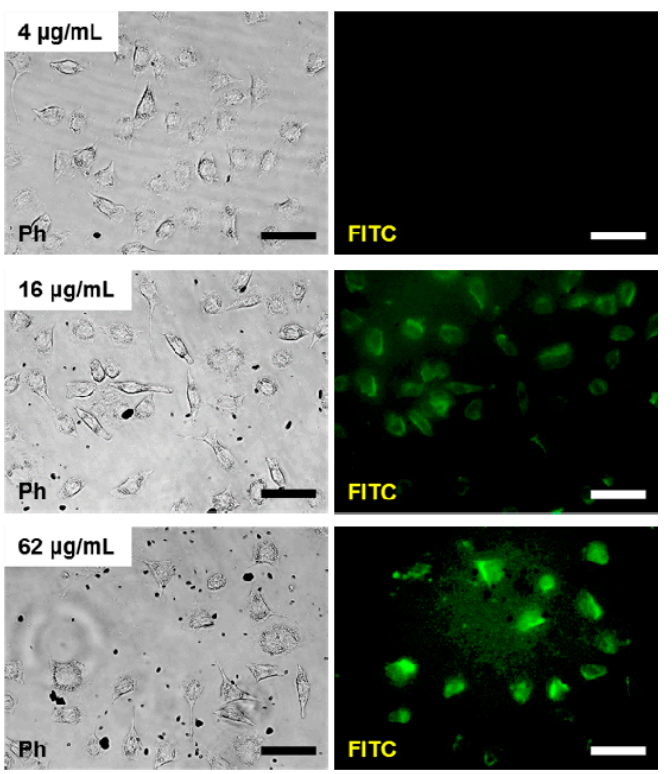

(b)

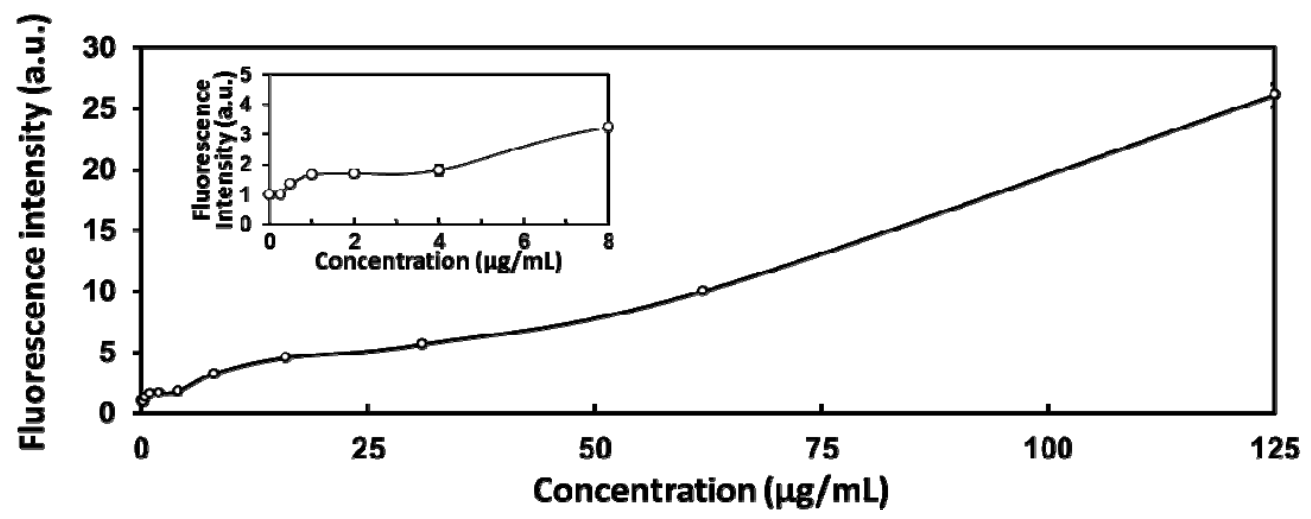

Figure 3. (a) Representative fluorescence microscopy images of oxidized DCF fluorescence in L-929 fibroblasts treated with various concentrations of layered $\mathrm{BP}(0,4,8,16,31$ and $62 \mu \mathrm{g} / \mathrm{mL})$ for $24 \mathrm{~h}$; and (b) quantification of oxidized DCF fluorescence intensity. The scale bars are $100 \mu \mathrm{m}$. 


\subsection{Time-Dependent Cytotoxicity of Layered BP}

To further evaluate the toxic effects of layered BPs on cells, we observed the morphological changes of L-929 fibroblasts and estimated the number of live cells. The time-lapse images of cells, treated with $10 \mu \mathrm{g} / \mathrm{mL}$ of layered BP for an initial $12 \mathrm{~h}$ at an interval of $1 \mathrm{~h}$, are shown in Figure $4 \mathrm{a}$. The number of live cells was estimated by quantifying the ratio of the number of attached cells to the total number of cells (Figure $4 \mathrm{~b}$ ). Because adherent cells, including fibroblastic cells, have to be attached to appropriate substrates in order to survive, the cells, which did not show typical fibroblastic morphology, were considered to be dead [18-22]. It was observed that the number of cells with apoptotic morphology (marked in red) increased throughout incubation with layered BPs for the initial $12 \mathrm{~h}$ (Figure 4a). In particular, the live cells decreased significantly $(p<0.05)$ after $6 \mathrm{~h}$ of incubation with layered BPs (Figure 4 b). The morphological changes were clearly observed by comparing optical microscopy images, taken every hour for $12 \mathrm{~h}$ (Figure 4c). These results implied that the cytotoxicity of layered BPs is also dependent on their exposure time.

(a)
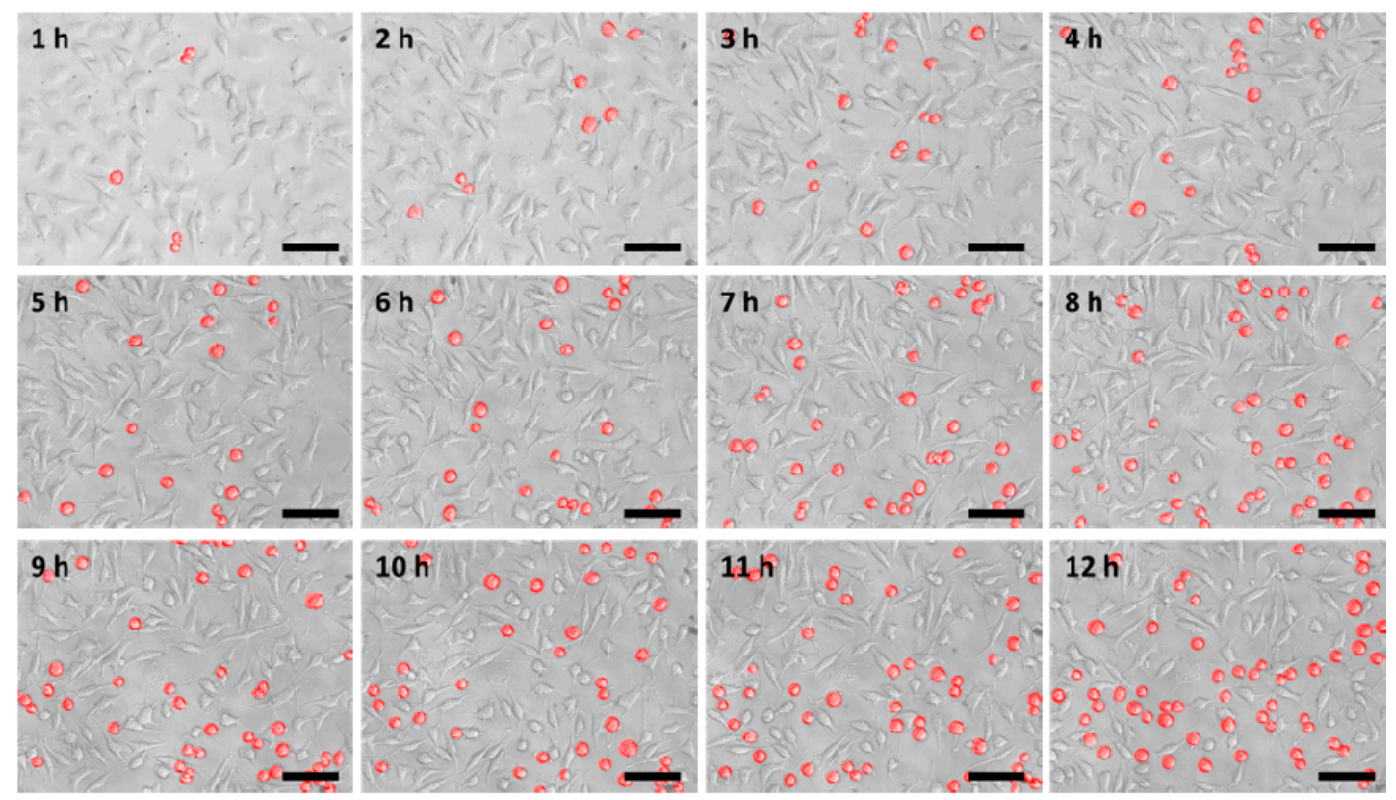

(b)

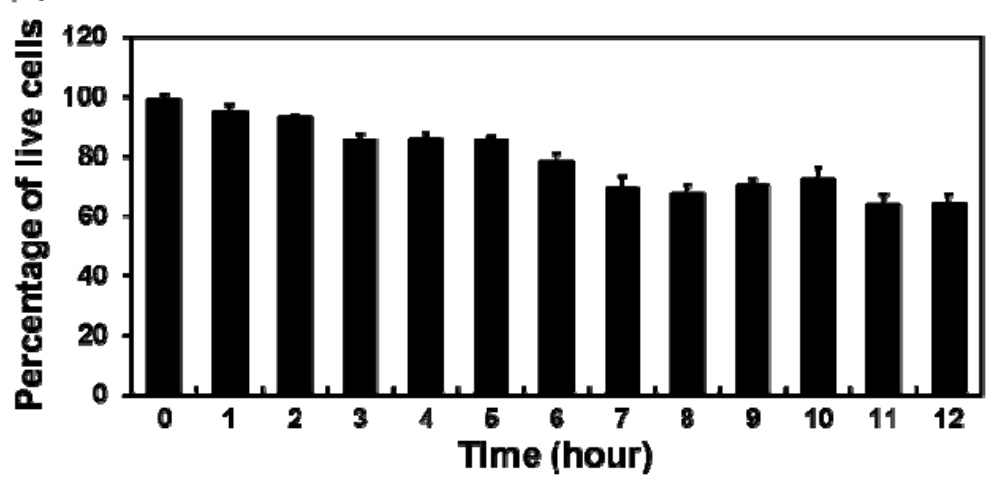

(c)

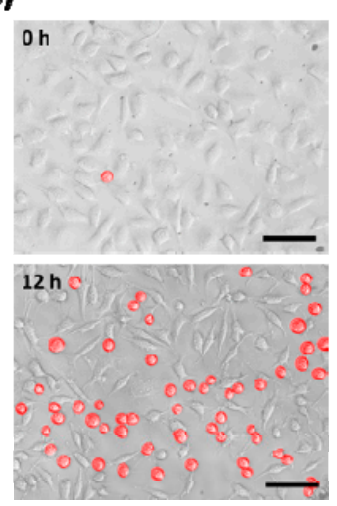

Figure 4. (a) Time-lapse images of L-929 cells treated with $10 \mu \mathrm{g} / \mathrm{mL}$ of layered BP for an initial $12 \mathrm{~h}$ at an interval of $1 \mathrm{~h}$; (b) Quantification of the percentage of live cells for $12 \mathrm{~h}$; (c) Optical microscopy images of L-929 fibroblasts treated with $10 \mu \mathrm{g} / \mathrm{mL}$ of layered BP for 0 and $12 \mathrm{~h}$. The scale bars are $100 \mu \mathrm{m}$. 
The cell viability of L-929 fibroblasts, incubated with layered BP for 48 and $72 \mathrm{~h}$, was evaluated to further examine the time-dependent cytotoxicity of layered BP, as shown in Figure 5a,b, respectively. The cytotoxic effects of layered BPs after 48 and $72 \mathrm{~h}$ are also dose-dependent, which is similar to the results after $24 \mathrm{~h}$. Additionally, the cell viability after 48 and $72 \mathrm{~h}$ decreased more than it did after $24 \mathrm{~h}$, as the incubation time with layered BPs had increased, and the decrease in cell viability after $72 \mathrm{~h}$ was more significant than after $48 \mathrm{~h}$. At a concentration of $16 \mu \mathrm{g} / \mathrm{mL}$, the cell viability after 48 and $72 \mathrm{~h}$ decreased to approximately $60 \%$ and $45 \%$ of the control, respectively. These results indicated that the cytotoxic effects of layered BPs were also dependent on exposure time. Consequently, it was revealed that the layered BP exhibited dose- and time-dependent cytotoxicity, as a result of membrane disruption and oxidative stress-mediated metabolic activity reduction caused by the accumulation of intracellular ROS as well as the interactions between layered BPs and cells. However, it is worth noting that the layered BPs were not significantly cytotoxic at concentrations lower than $4 \mu \mathrm{g} / \mathrm{mL}$, suggesting that layered BPs in the range of only a few $\mu \mathrm{g} / \mathrm{mL}$ can be effectively used in biomedical applications, such as therapeutic delivery carriers and imaging agents. Furthermore, to improve biocompatibility and biological activity, BPs can be conjugated or modified with various functional compounds, such as biocompatible polymers, nanoparticles and drugs $[1,10,12,15]$. It has been revealed that the encapsulation of BPs with poly(lactic-co-glycolic acid), a biodegradable polymer, allows not only the enhancement of biocompatibility, but also the degradation of nontoxic phosphate and phosphonate [12]. These results indicated that, although the cytotoxicity of BPs is closely dependent on their concentration and exposure time, the BPs with the desirable modification can be compatibly employed in biomedical applications, even at concentrations higher than $8 \mu \mathrm{g} / \mathrm{mL}$. In summary, it is suggested that BP has a promising potential as a biomedical material.

(a)

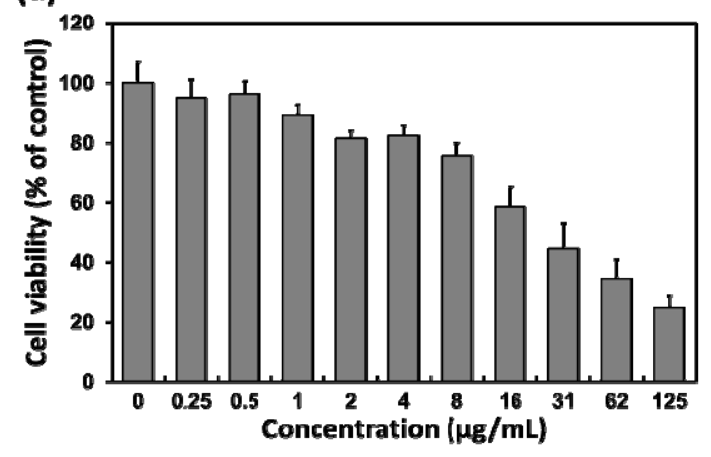

(b)

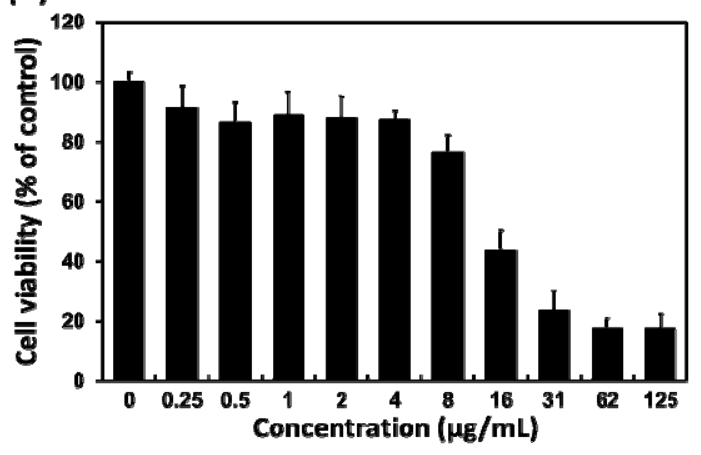

Figure 5. Cell viability profiles of L-929 fibroblasts after (a) 48 and (b) $72 \mathrm{~h}$ of incubation with various concentrations of layered BP.

\section{Conclusions}

This study aimed to investigate the dose- and time-dependent cytotoxicity of layered BPs against L-929 fibroblasts. It was revealed that the cytotoxicity of layered BPs was proportionally dependent on their concentration and exposure time. These cytotoxic effects of layered BPs are found to be due to both oxidative stress-mediated enzyme activity reduction and membrane disruption. On the other hand, the cytotoxicity of layered BPs is not significant at concentrations lower than $4 \mu \mathrm{g} / \mathrm{mL}$. Taken together, this work suggests that layered BPs can be effectively used in biomedical applications, such as therapeutic delivery carriers and imaging agents, although further comprehensive studies are undoubtedly necessary to fundamentally explore and understand the more detailed mechanisms behind the toxic effects of BPs.

Author Contributions: S.-J.S. and Y.C.S. designed the experiments, performed the in vitro assays and drafted the manuscript. H.U.L. carried out the preparation and characterization of layered BPs. B.K. performed the statistical 
analysis and helped to interpret the data. D.-W.H. and D.L. conceived of the study, participated in its design and coordination, and helped to draft the manuscript. All authors read and approved the final manuscript.

Funding: This work was supported by a 2-year research grant from Pusan National University.

Conflicts of Interest: The authors declare no conflict of interest.

\section{References}

1. Tao, W.; Zhu, X.; Yu, X.; Zeng, X.; Xiao, Q.; Zhang, X.; Ji, X.; Wang, X.; Shi, J.; Zhang, H. Black phosphorus nanosheets as a robust delivery platform for cancer theranostics. Adv. Mater. 2017, 29, 1603276. [CrossRef] [PubMed]

2. Shin, Y.C.; Song, S.-J.; Hong, S.W.; Jeong, S.J.; Chrzanowski, W.; Lee, J.-C.; Han, D.-W. Multifaceted biomedical applications of functional graphene nanomaterials to coated substrates, patterned arrays and hybrid scaffolds. Nanomaterials 2017, 7, 369. [CrossRef] [PubMed]

3. Chen, Y.; Ren, R.; Pu, H.; Chang, J.; Mao, S.; Chen, J. Field-effect transistor biosensors with two-dimensional black phosphorus nanosheets. Biosens. Bioelectron. 2017, 89, 505-510. [CrossRef] [PubMed]

4. Li, C.; Xie, Z.; Chen, Z.; Cheng, N.; Wang, J.; Zhu, G. Tunable bandgap and optical properties of black phosphorene nanotubes. Materials 2018, 11, 304. [CrossRef] [PubMed]

5. Xia, F.; Wang, H.; Jia, Y. Rediscovering black phosphorus as an anisotropic layered material for optoelectronics and electronics. Nat. Commun. 2014, 5, 4458. [CrossRef] [PubMed]

6. Engel, M.; Steiner, M.; Avouris, P. Black phosphorus photodetector for multispectral, high-resolution imaging. Nano Lett. 2014, 14, 6414-6417. [CrossRef] [PubMed]

7. Lee, T.H.; Kim, S.Y.; Jang, H.W. Black phosphorus: Critical review and potential for water splitting photocatalyst. Nanomaterials 2016, 6, 194. [CrossRef] [PubMed]

8. Jiang, X.-F.; Zeng, Z.; Li, S.; Guo, Z.; Zhang, H.; Huang, F.; Xu, Q.-H. Tunable broadband nonlinear optical properties of black phosphorus quantum dots for femtosecond laser pulses. Materials 2017, 10, 210. [CrossRef] [PubMed]

9. Chen, W.; Ouyang, J.; Liu, H.; Chen, M.; Zeng, K.; Sheng, J.; Liu, Z.; Han, Y.; Wang, L.; Li, J. Black phosphorus nanosheet-based drug delivery system for synergistic photodynamic/photothermal/chemotherapy of cancer. Adv. Mater. 2017, 29, 1603864. [CrossRef] [PubMed]

10. Sun, Z.; Xie, H.; Tang, S.; Yu, X.F.; Guo, Z.; Shao, J.; Zhang, H.; Huang, H.; Wang, H.; Chu, P.K. Ultrasmall black phosphorus quantum dots: Synthesis and use as photothermal agents. Angew. Chem. 2015, 127, 11688-11692. [CrossRef]

11. Wang, H.; Yang, X.; Shao, W.; Chen, S.; Xie, J.; Zhang, X.; Wang, J.; Xie, Y. Ultrathin black phosphorus nanosheets for efficient singlet oxygen generation. J. Am. Chem. Soc. 2015, 137, 11376-11382. [CrossRef] [PubMed]

12. Shao, J.; Xie, H.; Huang, H.; Li, Z.; Sun, Z.; Xu, Y.; Xiao, Q.; Yu, X.-F.; Zhao, Y.; Zhang, H. Biodegradable black phosphorus-based nanospheres for in vivo photothermal cancer therapy. Nat. Commun. 2016, 7, 12967. [CrossRef] [PubMed]

13. Lee, H.U.; Park, S.Y.; Lee, S.C.; Choi, S.; Seo, S.; Kim, H.; Won, J.; Choi, K.; Kang, K.S.; Park, H.G. Black phosphorus (BP) nanodots for potential biomedical applications. Small 2016, 12, 214-219. [CrossRef] [PubMed]

14. Mu, X.; Wang, J.-Y.; Bai, X.; Xu, F.; Liu, H.; Yang, J.; Jing, Y.; Liu, L.; Xue, X.; Dai, H. Black phosphorus quantum dot induced oxidative stress and toxicity in living cells and mice. ACS Appl. Mater. Interfaces 2017, 9, 20399-20409. [CrossRef] [PubMed]

15. Lv, R.; Yang, D.; Yang, P.; Xu, J.; He, F.; Gai, S.; Li, C.; Dai, Y.; Yang, G.; Lin, J. Integration of upconversion nanoparticles and ultrathin black phosphorus for efficient photodynamic theranostics under $808 \mathrm{~nm}$ near-infrared light irradiation. Chem. Mater. 2016, 28, 4724-4734. [CrossRef]

16. Latiff, N.M.; Teo, W.Z.; Sofer, Z.; Fisher, A.C.; Pumera, M. The cytotoxicity of layered black phosphorus. Chem. Eur. J. 2015, 21, 13991-13995. [CrossRef] [PubMed]

17. Zhang, X.; Zhang, Z.; Zhang, S.; Li, D.; Ma, W.; Ma, C.; Wu, F.; Zhao, Q.; Yan, Q.; Xing, B. Size effect on the cytotoxicity of layered black phosphorus and underlying mechanisms. Small 2017, 13, 1701210. [CrossRef] [PubMed] 
18. Kimmel, K.A.; Carey, T.E. Altered expression in squamous carcinoma cells of an orientation restricted epithelial antigen detected by monoclonal antibody A9. Cancer Res. 1986, 46, 3614-3623. [PubMed]

19. Giancotti, F.G.; Ruoslahti, E. Integrin signaling. Science 1999, 285, 1028-1033. [CrossRef] [PubMed]

20. Tseng, Y.; Kole, T.P.; Lee, S.-H.J.; Wirtz, D. Local dynamics and viscoelastic properties of cell biological systems. Curr. Opin. Colloid Interface Sci. 2002, 7, 210-217. [CrossRef]

21. Hood, J.D.; Cheresh, D.A. Role of integrins in cell invasion and migration. Nat. Rev. Cancer 2002, 2, 91-100. [CrossRef] [PubMed]

22. Jin, H.; Pi, J.; Huang, X.; Huang, F.; Shao, W.; Li, S.; Chen, Y.; Cai, J. BMP2 promotes migration and invasion of breast cancer cells via cytoskeletal reorganization and adhesion decrease: An AFM investigation. Appl. Microbiol. Biotechnol. 2012, 93, 1715-1723. [CrossRef] [PubMed]

23. Sun, C.; Wen, L.; Zeng, J.; Wang, Y.; Sun, Q.; Deng, L.; Zhao, C.; Li, Z. One-pot solventless preparation of PEGylated black phosphorus nanoparticles for photoacoustic imaging and photothermal therapy of cancer. Biomaterials 2016, 91, 81-89. [CrossRef] [PubMed]

24. Ge, S.; Zhang, L.; Wang, P.; Fang, Y. Intense, stable and excitation wavelength-independent photoluminescence emission in the blue-violet region from phosphorene quantum dots. Sci. Rep. 2016, 6, 27307. [CrossRef] [PubMed]

25. Wang, X.; Jones, A.M.; Seyler, K.L.; Tran, V.; Jia, Y.; Zhao, H.; Wang, H.; Yang, L.; Xu, X.; Xia, F. Highly anisotropic and robust excitons in monolayer black phosphorus. Nat. Nanotechnol. 2015, 10, 517-521. [CrossRef] [PubMed]

26. Mahmoudi, M.; Simchi, A.; Milani, A.S.; Stroeve, P. Cell toxicity of superparamagnetic iron oxide nanoparticles. J. Colloid Interface Sci. 2009, 336, 510-518. [CrossRef] [PubMed]

27. Chang, Y.; Yang, S.-T.; Liu, J.-H.; Dong, E.; Wang, Y.; Cao, A.; Liu, Y.; Wang, H. In vitro toxicity evaluation of graphene oxide on A549 cells. Toxicol. Lett. 2011, 200, 201-210. [CrossRef] [PubMed]

28. Akhavan, O.; Ghaderi, E.; Akhavan, A. Size-dependent genotoxicity of graphene nanoplatelets in human stem cells. Biomaterials 2012, 33, 8017-8025. [CrossRef] [PubMed]

29. Ma, J.; Liu, R.; Wang, X.; Liu, Q.; Chen, Y.; Valle, R.P.; Zuo, Y.Y.; Xia, T.; Liu, S. Crucial role of lateral size for graphene oxide in activating macrophages and stimulating pro-inflammatory responses in cells and animals. ACS Nano 2015, 9, 10498-10515. [CrossRef] [PubMed]

30. Hu, W.; Peng, C.; Lv, M.; Li, X.; Zhang, Y.; Chen, N.; Fan, C.; Huang, Q. Protein corona-mediated mitigation of cytotoxicity of graphene oxide. ACS Nano 2011, 5, 3693-3700. [CrossRef] [PubMed]

31. Schneider, Y.; Chabert, P.; Stutzmann, J.; Coelho, D.; Fougerousse, A.; Gossé, F.; Launay, J.F.; Brouillard, R.; Raul, F. Resveratrol analog (Z)-3,5,4'-trimethoxystilbene is a potent anti-mitotic drug inhibiting tubulin polymerization. Int. J. Cancer 2003, 107, 189-196. [CrossRef] [PubMed] 